\title{
Kombinasi Hormon Ovaprim Dengan Ekstrak Hipofisa Ayam Sbroiler Terhadap Waktu Latensi Ovulasi (Hatching rate) Ikan Lele Sangkuriang (Clarias gariepinus var. sangkuriang)
}

\author{
${ }^{1}$ Aan Aryanti Sandra, ${ }^{2}$ Muhammad Sugihartono, dan ${ }^{* 2}$ Muarofah Ghofur \\ ${ }^{1}$ Alumni Program Studi Budidaya Perairan, Fakultas Pertanian Universitas Batanghari \\ ${ }^{2}$ Program Studi Budidaya Perairan Fakultas Pertanian Universitas Batanghari \\ Jl. Slamet Riyadi, Broni, Jambi, 36122. Telp. +6074160103 \\ ${ }^{* 2}$ Email Korespondensi : muarofah_ghofur@yahoo.com
}

\begin{abstract}
Sangkuriang catfish (Clarias gariepinus var. Sangkuriang) is one of the freshwater fish that is widely consumed and cultivated in Indonesia (Pratiwi, 2014). To increase catfish production can be done by applying artificial spawning techniques. Artificial spawning can be done by stimulation using Ovaprim hormones. Ovaprim has GnRH and antidopamine content. However, this ovaprim hormone has an expensive price which ranges from Rp. 28,000-30,000 / ml, so it is necessary to study alternative ingredients using broiler chicken hypophysis. The study design was carried out using a completely randomized design model (CRD) consisting of 5 treatments and 3 replications, each treatment was P1 Ovaprim Hormone Treatment $0.3 \mathrm{ml} / \mathrm{Kg}$ (100\%), P2 Ovaprim Hormone Treatment $0.225 \mathrm{ml} / \mathrm{Kg}(75 \%)+$ Broiler chicken hypophysis $125 \mathrm{mg} / \mathrm{Kg}$ (25\%), Ovaprim Hormone P3 Treatment $0.15 \mathrm{ml} / \mathrm{Kg}(50 \%)+$ Broiler chicken hypophysis $250 \mathrm{mg} / \mathrm{Kg}$ (50\%), P4 Ovaprim Hormone Treatment $0.075 \mathrm{ml} / \mathrm{Kg}(25 \%)+$ Broiler chicken hypophysis $375 \mathrm{mg} / \mathrm{Kg}(75 \%)$, P5 treatment of Broiler chicken hypophysis $500 \mathrm{mg} / \mathrm{Kg}$ (100\%). The result of this research with time fasten is C treatment (ovaprim 50\% and chicken broiler hypophisa 50\%) in 7 hours and 36 minutes.
\end{abstract}

Keywords : Ovaprim, Antidopamine, GnRH, Hypophysis, Spawning

\begin{abstract}
Abstrak. Ikan lele sangkuriang (Clarias gariepinus var. sangkuriang) adalah satu jenis ikan yang hidup di air tawar dan banyak dikonsumsi dan dibudidayakan di Indonesia (Pratiwi, 2014). Agar produksi ikan lele meningkat maka dapat dilakukan dengan cara menerapkan teknik Pemijahan buatan. Pemijahan buatan bisa dilakukan dengan perangsangan menggunakan hormon berupa Ovaprim. Ovaprim memiliki kandungan GnRH dan antidopamine. Namun, harga hormon ovaprim ini relative mahal yaitu berkisar antara Rp 28.000-30.000/ml, sehingga perlu dipelajari alternatif bahan dengan menggunakan hipofisa ayam broiler. Rancangan penelitian yang dilakukan menggunakan model Rancangan Acak Lengkap (RAL) yang terdiri dari 5 perlakuan dan 3 kali ulangan, masing-masing perlakuan tersebut adalah Perlakuan P1 Hormon Ovaprim 0,3 ml/Kg (100\%), Perlakuan P2 Hormon Ovaprim $0,225 \mathrm{ml} / \mathrm{Kg}(75 \%)+$ Hipofisa ayam broiler $125 \mathrm{mg} / \mathrm{Kg}(25 \%)$, Perlakuan P3 Hormon Ovaprim 0,15 ml/Kg (50\%) + Hipofisa ayam broiler $250 \mathrm{mg} / \mathrm{Kg}(50 \%)$, Perlakuan P4 Hormon Ovaprim 0,075 ml/Kg (25\%) + Hipofisa ayam broiler $375 \mathrm{mg} / \mathrm{Kg}(75 \%)$, Perlakuan P5 Hipofisa ayam Broiler $500 \mathrm{mg} / \mathrm{Kg}(100 \%)$. Hasil penelitian menunjukkan bahwa aktu alten yang paling cepat adalah perlakuan $\mathrm{C}$ dengan dosis ovaprim 50\% dan hipofisa ayam broiler 50\% dengan waktu 7 jam 36 menit.
\end{abstract}

Kata Kunci : Ovaprim, Antidopamin, GnRH, Hipofisa, Pemijahan

\section{PENDAHULUAN}

Ikan lele sangkuriang (Clarias gariepinus var. sangkuriang) merupakan salah satu ikan air tawar yang banyak dikonsumsi dan dibudidayakan di Indonesia (Pratiwi, 2014). Untuk mendapatkan jumlah produksi yang diinginkan pada budidaya ikan lele ini dapat dilakukan dengan sistem budidaya intensif dengan menerapkan teknik pemijahan buatan secara terukur dan terencana siklusnya.

Salah satu teknik pemijahan yang bisa dilakukan secara buatan adalah dengan perangsangan menggunakan hormon berupa Ovaprim. Ovaprim mempunyai komposisi hormon GnRH dan antidopamine. GnRH mempunyai fungsi sebagai perangsang hipofisa untuk melepaskan gonadotropin hormone $(\mathrm{GtH})$ berupa Follicle Stimulating Hormon (FSH, GtH I) dan Luteinizing Hormone (LH, GtH II) (Schulz, 1995). FSH memiliki fungsi untuk mengatur proses sintesis kuning telur dan proses gametogenesis pada ikan jantan. Sedangkan LH memiliki fungsi mengatur proses pematangan telur pada tahap akhir dan spermiasi (Slater et al.1994; Moberg et al. 1995; Mylonas dan Zohar,2001).FSH mempunyai fungsi mengatur Proses sintesis kuning telur dan proses gametogenesis pada ikan jantan. Sedangkan LH mempunyai fungsi mengatur proses pematangan telur tahap akhir dan spermiasi (Slater et al, 1994; Moberg et al, 1995; Mylonas dan zohar, 2001). Tetapi, harga hormone ovaprim saat ini relative mahal, berkisar Rp. 28.000,- hingga Rp. 30.000 ,- per milliliter, sehingga perlu ada hormon alternatif dengan harga yang memiliki fungsi dalam aktivitas seksual (Pemijahan) yang mampu mengurangi pengunaan Hormon Ovaprim dalam teknik pemijahan buatan.

Indonesia adalah salah satu negara terbesar penghasil ayam broiler. Hipofisa ayam broiler juga memiliki kemampuan untuk mensekresi hormon gonadotropin (FSH dan LH) (Andalusia et al, 2008).

Azhar dan Masrizal (2007) telah mencoba menggunakan hipofisa ayam untuk mempercepat masa laten pemijahan ikan lele. Dosis yang digunakan adalah $300 \mathrm{mg} / \mathrm{kg}, 400 \mathrm{mg} / \mathrm{kg}, 500 \mathrm{mg} / \mathrm{kg}, 700 \mathrm{mg} / \mathrm{kg} \mathrm{dan} 800 \mathrm{mg} / \mathrm{kg}$ berat badan resipien. Eksperimen yang dilakukan oleh Azhar dan Masrizal (2007) menunjukkan kelenjar hipofisa ayam 
Aan Aryanti Sandra, Muhammad Sugihartono, dan Muarofah Ghofur. Kombinasi Hormon Ovaprim Dengan Ekstrak Hipofisa Ayam Sbroiler Terhadap Waktu Latensi Ovulasi (Hatching rate) Ikan Lele Sangkuriang (Clarias gariepinus var. sangkuriang)

broiler ini dapat mempercepat waktu latensi ovulasi induk ikan lele dumbo, meningkatkan prosentase ovulasi, tingkat kematangan telur. Penggunaan dosis yang optimal dalam penyuntikkan ikan lele adalah $743,75 \mathrm{mg} / \mathrm{kg}$ (Azhar dan Mazrizal, 2007). Oleh karena itu untuk mengetahui efektivitas kombinasi hormon ovaprim dengan hipofisa ayam broiler maka perlu dilakukan penelitian tentang "Kombinasi hormon ovaprim dengan ekstrak hipofisa ayam broiler terhadap waktu latensi ovulasi ikan lele sangkuriang (Clarias gariepinus var. sangkuriang)"

\section{METODOLOGI PENELITIAN}

Penelitian kombinasi Hormon ovaprim dengan ekstrak hipofisa ayam broiler Terhadap Waktu Latensi Ovulasi Ikan lele sangkuriang (C. gariepinus var. sangkuriang) dilaksanakan pada tanggal 15 sampai 17 Januari 2020. Tempat penelitian ini dilaksanakan yaitu di Balai Perikanan Budidaya Air Tawar (BPBAT) Sungai Gelam, Provinsi Jambi

Peralatan yang digunakan dalam penelitian ini adalah bak semen sebanyak 15 buah dengan ketinggian air 50 $\mathrm{cm}$, seperangkat alat seksio, penggerus hipofisa, sentrifuge, mangkok plastik kecil, blower sebagai aerator, timbangan biasa dan timbangan analitik, gelas ukur, spuit ukuran $1 \mathrm{ml}$, kateter, dan cawan petri.

Bahan yang digunakan adalah ikan lele sangkuriang betina sebanyak 15 ekor yang telah matang gonad.. Hormon Ovapim sintetik, Untuk kelenjar hipofisa digunakan kelenjar hipofisa ayam broiler yang diambil dari kepala ayam broiler berumur lebih kurang 40 hari. Bahan - bahan lain yaitu alkohol $96 \%$ larutan fisiologis $(\mathrm{NaCl} 0,9 \%)$.

Rancangan penelitian yang akan dilakukan menggunakan model Rancangan Acak Lengkap (RAL) yang terdiri dari 5 perlakuan dan 3 kali ulangan, masing-masing perlakuan tersebut adalah Perlakuan P1 Hormon Ovaprim 0,3 $\mathrm{ml} / \mathrm{Kg}$ (100\%), Perlakuan P2 Hormon Ovaprim 0,225 ml/Kg (75\%) + Hipofisa ayam broiler $125 \mathrm{mg} / \mathrm{Kg}(25 \%)$, Perlakuan P3 Hormon Ovaprim 0,15 ml/Kg (50\%) + Hipofisa ayam broiler $250 \mathrm{mg} / \mathrm{Kg}(50 \%)$, Perlakuan P4 Hormon Ovaprim 0,075 ml/Kg (25\%) + Hipofisa ayam broiler 375 mg/Kg (75\%), Perlakuan P5 Hipofisa ayam Broiler 500 $\mathrm{mg} / \mathrm{Kg}(100 \%)$.

Kegiatan Penelelitian dimulai dari mengambil Kelenjar hipofisa ayam broiler dengan jalan membuka tengkorak kepala ayam tersebut. Kemudian kelenjar hipofisa ini diambil, dicuci dengan alkohol dan dimasukkan ke dalam botol yang telah diisi dengan alkohol $96 \%$ untuk dikumpulkan atau disimpan sementara sebelum digunakan. Pada waktu yang akan digunakan, kelenjar hipofisa ayam broiler ditimbang berdasarkan dosis perlakuan (125 mg, 250 $\mathrm{mg}, 375 \mathrm{mg}, 500 \mathrm{mg}$ ) menggunakan timbangan analitik, setelah ditimbang kelenjar hipofisa dihaluskan dengan penggerus dalam cawan petri dan kemudian ditambahkan larutan fisiologis $\mathrm{NaCl} 0,9 \%$ masing - masing $1,5 \mathrm{ml}$. Ekstrak hipofisa dimasukkan kedalam gelas tabung dan disentrifuse dengan kecepatan $3000 \mathrm{rpm}$ selama 2-5 menit, setelah itu akan terbentuk dua lapisan (cairan bening dan endapan). Cairan yang digunakan adalah cairan bening (Efrizal et al., 1998). Kemudian siapkan hormon ovaprim dengan dosis perlakuan $(0,075 \mathrm{ml}, 0,15$ 0,225 ml, dan 0,3 $\mathrm{ml})$.

Selanjutnya penyuntikan induk dilakukan dibagian punggung dengan kemiringan jarum suntik $40-45^{\circ} \mathrm{C}$ dan kedalaman jarum suntik $\pm 1 \mathrm{~cm}$ atau di sesuaikan dengan besar kecilnya tubuh ikan. Setelah ovaprim didorong masuk, jarum suntik dicabut lalu bekas suntik ditutup dengan jari sambil ditekan secara perlahan-lahan beberapa saat agar ovaprim tidak keluar. Penyuntikkan terhadap ikan uji dilakukan satukali dengan dosis yang sudah ditetapkan, setelah itu induk ikan dimasukkan kembali didalam bak penampung dan dibiarkan selama 6 jam untuk proses pengambilan telur melalui pengurutan. (Sinjal, 2014). Pengecekkan ovulasi dilakukan setelah 6 jam dari penyuntikkan. Ovulasi induk ikan uji akan terjadi apabila perut induk tersebut diurut ke arah kloaka dan akan mengeluarkan telur melalui lubang genitalnya. Jika belum ada tanda-tanda ovulasi, maka dilakukan pengecekan ovulasi setiap 30 menit sampai ovulasi terjadi. Berdasarkan pengamatan pada awal penelitian, telah diketahui jarak antara waktu penyuntikan dengan waktu ovulasi (Sandi, 2019).

\section{Waktu Latensi Ovulasi}

Waktu latensi ovulasi dapat diketahui menggunakan rumus (Setyaningrum dan Wibowo, 2016), berikut : Waktu Laten $(\mathrm{Jam})=$ Waktu Ovulasi - Waktu Penyuntikan Akhir

\section{Kualitas Air}

Parameter kualitas air yang akan diamati yakni : Suhu, $\mathrm{O}_{2}$, dan $\mathrm{pH}$. Pengukuran suhu dilakukan setiap hari selama penelitian menggunakan thermometer dan water test kit.

\section{Analisis Data}

Untuk melihat pengaruh kombinasi Hormon Ovaprim dengan ekstrak hipofisa ayam broiler respon Ovulasi dan daya tetas telur ikan Lele Sangkuriang (Clarias gariepinus var. sangkuriang) akan dianalisis dengan menggunakan sidik ragam (ANOVA) pada taraf 5\%, Jika terdapat pengaruh atau beda nyata kemudian dilanjutkan dengan Uji jarak berganda duncan (DNMRT). Serta data lain yang akan menunjang analisa penelitian akan dilakukan secara deskripif. 
Aan Aryanti Sandra, Muhammad Sugihartono, dan Muarofah Ghofur. Kombinasi Hormon Ovaprim Dengan Ekstrak Hipofisa Ayam Sbroiler Terhadap Waktu Latensi Ovulasi (Hatching rate) Ikan Lele Sangkuriang (Clarias gariepinus var. sangkuriang)

\section{Waktu Latensi Ovulasi (Jam, Menit)}

\section{HASIL DAN PEMBAHASAN}

Berdasarkan Data Penelitian dilihat bahwa Perlakuan P3 (ovaprim 50\% + 50\% hipofisa ayam Broiler) memberikan waktu ovulasi lebih cepat dibandingkan perlakuan P1 (ovaprim 100\%), P2 (ovaprim 75\% + 25\% hipofisa ayam Broiler). Namun Pada Perlakuan P5 (Hipofisa ayam broiler 100\%) ikan lele sangkuriang (C. gariepinus var. sangkuriang) tidak mengalami ovulasi sama sekali, hal ini berbeda dengan perlakuan P4 (Ovaprim $25 \%+75 \%$ Hipofisa) yang hanya ovulasi pada ulangan 1 sedangkan untuk ulangan 2 dan 3 tidak mengalami ovulasi. Hal ini mungkin disebabkan karena dosis yang digunakan tidak tepat atau kandungan LH (Luteinizing Hormone) dalam ekstrak hipofisa ayam Broiler tidak cukup untuk membuat ikan lele sangkuriang mengalami ovulasi mengingat ayam broiler yang digunakan sebagai donor berumur 40 hari dengan aktivitas reproduksi yang rendah dan dalam masa penyempurnaan organ reproduksi. Indira dan Wibowo (1998) dalam Muhammad et al. (2001) menjelaskan bahwa kemampuan ovulasi ikan sangat berkaitan dengan penggunaan dosis yang efektif untuk tiap spesies. Menurut Lam (1982) dan Matty (1985) dalam Azhar dan Masrizal (2007) Hormon LH (Luteinizing Hormone) mempunyai peran untuk merangsang proses ovulasi dan pemijahan induk ikan betina.

Tabel 1. Hasil analisis Uji Lanjut Jarak Berganda Duncan (DNMRT) Waktu Latensi Ovulasi

\begin{tabular}{ccc}
\hline Perlakuan & Rata-rata & Notasi 5\% \\
\hline P5 (Hipofisa Ayam Broiler 100\%) & 0 & $\mathrm{~A}$ \\
P4 (Ovaprim 25\% + Hipofisa Ayam Broiler 75\%) & 3,38 & $\mathrm{Ab}$ \\
P3 (Ovaprim 50\% + Hipofisa Ayam Broiler 50\%) & 7,36 & $\mathrm{Bc}$ \\
P2 (Ovaprim 75\% + Hipofisa Ayam Broiler 25\%) & 8,43 & $\mathrm{C}$ \\
P1 (Ovaprim 100\%) & 9,2 & $\mathrm{C}$ \\
\hline
\end{tabular}

Keterangan : huruf yang sama pada kolom yang sama menunjukkan tidak berbeda nyata

Berdasarkan hasil analisis sidik ragam Anova kombinasi ovaprim dengan ekstrak hipofisa ayam broiler berpengaruh nyata terhadap waktu latensi ovulasi ikan lele sangkuriang (C. gariepinus var. sangkuriang) dimana Fhitung >Ftabel $0.05 \%$. pada hasil uji lanjut jarak berganda duncan (DNMRT) perlakuan P5 dan P4 tidak menunjukkan perbedaaan yang signifikan namun perlakuan P5 Menunjukkan perbedaan yang sangat signifikan dengan perlakuan P1, P3, dan P2 pada taraf 5\%. Dari hasil penelitian ini menunjukkan bahwa induk ikan lele sangkuriang disuntik dengan Kombinasi ovaprim 50\% $+50 \%$ hipofisa ayam broiler menunjukkan hasil yang terbaik. Terjadinya Ovulasi pada perlakuan kombinasi hormon ovaprim $50 \%+50 \%$ hipofisa ayam broiler disebabkan ovaprim dan hipofisa ayam broiler bekerja secara sinergis, ovaprim sangat berperan dalam merangsang ovulasi pada ikan, karena ovaprim mengandung GnRH yang merangsang hipofisa untuk melepas gonadotropin hormon, dan sekresi gonadotropin dihambat oleh dopamine sehingga apabila dopamine dihambat oleh antagonisnya maka peranan dopamine akan terhenti dan sekresi gonadotropin akan meningkat (Harker dalam sukendi 2012). Gonadotropin yang dihasilkan akan menuju gonad dimana gonadotropin ini mengandung Folicle Stimulating Hormone (FSH) yang berperan dalam proses vitelogenesis dan Luteinizing Hormone (LH) Berperan dalam merangsang ovulasi dan akan mempercepat proses pematangan oosit pada tahap akhir. Sedangkan hipofisa ayam broiler juga mempunyai aktivitas untuk mensekresi hormon gonadotropin (FSH dan LH) (Andalusia dkk, 2008). Menurut Wadi (2018) Hipofisa ayam broiler mampu memperbesar diameter telur ikan lele dumbo. Ovulasi terjadi apabila proses vitelogenesis sempurna. Fujaya (2002) menjelaskan vitelogenesis dipengaruhi oleh hormon gonadotropin yang dihasilkan oleh kelenjar hipofisa vertebrata. Kelenjar ini merupakan kelenjar utama penghasil hormon, yang salah satunya adalah gonadotropin. Berdasarkan penelitian Nur et al. (2017) menjelaskan Diameter telur yang besar pada kombinasi Hcg $500 \mathrm{IU}+$ Ovaprim $0,7 \mathrm{ml} / \mathrm{kg}$ bobot badan disebabkan pemberian Hcg yang berfungsi untuk menyeragamkan kematangan akhir telur atau mempersiapkan telur yang matang untuk diovulasikan.

\section{Kualitas Air}

Data Hasil uji parameter kualitas Air untuk reproduksi dan penetasan telur ikan Lele Sangkuriang (Clarias gariepinus var. sangkuriang) disajikan dalam tabel berikut:

Tabel 2. Hasil Pengukuran Uji Kualitas Air Penelitian

\begin{tabular}{ccccccc}
\hline \multirow{2}{*}{ Parameter Uji } & \multicolumn{5}{c}{ Perlakuan } & \multirow{2}{*}{ Kisaran } \\
\cline { 2 - 6 } & P1 & P2 & P3 & P4 & P5 & \\
\hline Suhu $\left({ }^{\circ} \mathrm{C}\right)$ & 27,28 & 27,28 & 27,7 & 27,7 & 27,7 & $25-30^{\circ} \mathrm{C}(\mathrm{SNI}, 2014)$ \\
$\mathrm{DO}(\mathrm{mg} / \mathrm{L})$ & 4,6 & 7,8 & 7,1 & 6,8 & 6,6 & $>3 \mathrm{mg} / \mathrm{L}$ (SNI, 2014) \\
$\mathrm{pH}$ & 6,7 & 6,8 & 6,6 & 6,7 & 6,6 & $6,5-8$ (SNI, 2014) \\
\hline
\end{tabular}


Aan Aryanti Sandra, Muhammad Sugihartono, dan Muarofah Ghofur. Kombinasi Hormon Ovaprim Dengan Ekstrak Hipofisa Ayam Sbroiler Terhadap Waktu Latensi Ovulasi (Hatching rate) Ikan Lele Sangkuriang (Clarias gariepinus var. sangkuriang)

Dari data hasil uji kualitas air masih dalam kisaran layak untuk pemijahan, pemeliharaan dan penetasan telur ikan lele sangkuriang (Clarias gariepinus var. sangkuriang).

\section{KESIMPULAN}

Berdasarkan hasil penelitian yang telah dilakukan mengenai kombinasi hormon ovaprim dan ekstrak hipofisa ayam broiler, memberikan pengaruh terhadap waktu latensi tercepat pada dosis ovaprim $50 \%+50 \%$ hipofisa ayam broiler dengan waktu 7 jam 36 menit lebih cepat 2 jam 24 menit dibandingkan dengan penggunaan hormon ovaprim $100 \%$, namun pada perlakuan hipofisa ayam broiler $100 \%$ ikan lele sangkuriang (C. gariepinus var sangkuriang) tidak memgalami ovulasi. Penelitian ini memberikan pengaruh nyata berdasarkan hasil analisis sidik ragam Anova pada taraf 5\%.

\section{DAFTAR PUSTAKA}

Andalusia, R. A.S. Mubarak. Dan Y. Dhamayanti. 2008. Respon Pemberian Ekstrak Hipofisa Ayam Broiler Terhadap Waktu Latensi, Keberhasilan Pembuahan dan Penetasan Pada Penetasan Ikan Komet (Carassius auratus auratus). Jurnal Berkala Ilmiah Perikanan. Program Studi Budidaya Perairan Fakultas Kedokteran Hewan. Universitas Airlangga. Vol.3 No.1

Azhar dan Masrizal. 2007. Pengaruh Penyuntikan Ekstrak Kelenjar Hipofisa Ayam Broiler Terhadap Pemijahan Ikan Lele dumbo (Clarias gariepinus Burchell). Jurnal Peternakan Indonesia. 12(2):78-87.

Effrizal. 1998. Respon Ovulasi Ikan Lele Dumbo (Clarias gariepinus. B) Dari Berbagai Dosis Hormon LHRH-a, Fisheries Jurnal. Garing. Vol. 7 No. 2. Jurnal Fakultas Perikanan Universitas Bung Hatta. Padang.

Harker K. 1992. Pembiakan Kap dengan Menggunakan Ovaprim di India. Warta Akuakulture. Volume 2, No. 3

Lam, T.J. 1982. Applications of Endocrinology to Fish Culture. Can. J. Fish. Aquat. Sci, 39 : 111 - 137.

Matty, A.J. 1985. Fish Endocrinology. Croom Helm and Timber Press, London Sydney Portland - Oregon.

Moberg, GP. , Watson, JG., Doroshov, S., Papkoff H., dan Pavlick RJ. 1995 . Physiological Evidence For Two Sturgeon Gonadotropin in Acipenser transmontanus . Aquaculter, 135:27-39

Muhammad., Sunusi H. dan Ambas I. 2001. Pengaruh donor dan dosis kelenjar hipofisa terhadap ovulasi dan daya tetas telur ikan betok (Anabas testudineus Bloch). J. Sci\&Tech. 2(2): 14-22.

Mylonas, CC., dan Zohar, Y. 2001 . Use of GnRH-delivery Systems for The Control of Reproduction in Fish . Reviews in fish Biology and Fisheries, 10(4), 463-491.

Pratiwi, D.R. 2014. Aplikasi Effective Microorganism 10 (em10) untuk pertumbuhan ikan lele sangkuriang (Clarias gariepinus var. sangkuriang) di kolam budidaya lele jombang, tangerang. Skripsi. Jurusan biologi fakultas sains dan teknologi. Universitas islam negeri syarif hidayatullah jakarta.

Sandi , B.R. 2019 . Induksi Ovulasi dan Pemijahan Buatan Induk Ikan Patin Siam (Pangasionodon hypopthalmus Sauvage 1878) Dengan Kombinasi Hormon Ovaprim dan Oksitosin . Skripsi . Universitas Lampung.

Setyaningrum, N., dan E.S Wibowo. 2016. Potensi Reproduksi Ikan Air Tawar sebagai Baby Fish. Jurnal Biosfera. 33(2);85-91.

Sinjal, H. 2014. Efektivitas Ovaprim Terhadap Lama Waktu Pemijahan, Daya Tetas Telur dan Sintasan Larva Ikan Lele Dumbo (Clarias gariepinus). Jurnal Budidaya Perairan. Vol.2 No.1:14-21

Slater, C. Schreck, C.B. and Swanson, P. 1994 . Plasma Profiles of The Sex Steroids and Gonadotropin in Maturing Female Spring Chinook Salmon (Oncorhynchus tshawystcha) . Comp. Biochem . Physiol . 109.167-175.

Standar Nasional Indonesia. 2014. Produksi Benih Ikan Lele Dumbo (Clarias sp.) SNI. ICS 65.150. 6484.4

Sukendi. 2012. Fisiologi Reproduksi ikan. MM Press C. V. Mina Ma. Pekanbaru. $130 \mathrm{Hlm}$.

Wadi, H., M. Idris., Yusnaini. 2018. Respon Pemberian Ekstrak Hipofisa Ayam Broiler Dengan Dosis Berbeda Terhadap Ovulasi Ikan Lele Dumbo (Clarias gariepinus) Betina. Media Akuatika. Vol.3, No.2,617-629. 